\title{
DESENVOLVIMENTO DE UMA APLICAÇÃO DE GERENCIAMENTO DE PROJETOS ARQUITETÔNICOS BASEADA NO TOOLKIT HCD
}

FRANCISCO, Alesson Delmiro ${ }^{1}$

ANDRADE, Danyllo Gomes Figueredo de ${ }^{2}$

GOUVEIA, Roberta Macêdo Marques ${ }^{3}$

FRANCISCO, Alesson Delmiro; ANDRADE, Danyllo Gomes Figueredo de; GOUVEIA, Roberta Macêdo Marques. Desenvolvimento de Uma Aplicação de Gerenciamento de Projetos Arquitetônicos Baseada no Toolkit HCD. Revista Científica Multidisciplinar Núcleo do Conhecimento. Edição 03. Ano 02, Vol. 01. pp 238-248, Junho de 2017. ISSN:2448-0959

\section{RESUMO}

Este artigo apresenta o desenvolvimento de uma aplicação computacional de gerenciamento de projetos arquitetônicos, com base no Toolkit HCD (Human Centered Design), com vistas a auxiliar o gerenciamento de projetos de arquitetura. Dentre os objetivos do trabalho, tem-se o desenvolvimento de um protótipo, utilizando a plataforma proto.io, visando prover um meio de comunicação eficiente e confiável para arquitetos e clientes. A ferramenta de gerenciamento de projetos de arquitetura proposta neste trabalho dispõe de uma boa interface humano-computador, por meio dos critérios de usabilidade de Jakob Nielsen. Em relação à metodologia do trabalho, são contempladas as duas primeiras fases do Toolkit HCD, a fase "ouvir" e a fase

1 Departamento de Estatística e Informática - Universidade Federal Rural de Pernambuco (UFRPE).

2 Departamento de Estatística e Informática - Universidade Federal Rural de Pernambuco (UFRPE).

3 Departamento de Estatística e Informática - Universidade Federal Rural de Pernambuco (UFRPE). 
"criar", que são fundamentais para que se alcance um bom resultado na criação de produtos inovadores.

\section{INTRODUÇÃO}

$\mathrm{Na}$ época atual o tempo possui valor. A recompensa de trabalho é baseada na quantidade de tempo que trabalhamos e no valor que a hora possui. A necessidade de gerenciar as horas e as atividades se tornaram indispensáveis para a antecipação de contingências e para o desenvolvimento de um trabalho equilibrado. No contexto comercial a satisfação do cliente possui um peso considerável sobre as decisões.

$\mathrm{Na}$ área de arquitetura identificou-se com frequência problemas de insatisfação do cliente e mau gerenciamento de atividades e horas dos profissionais de arquitetura. Constatou-se também que os principais problemas são: a insatisfação do cliente nas entregas finais, soluções que não condizem com o que o cliente esperava, mau planejamento que geraram maior custo para o projeto, gargalos no processo de desenvolvimento do projeto (gerenciamento de feedback e clareza nas definições do projeto). A incapacidade do arquiteto de prever possíveis problemas provocam: insegurança do cliente no desenvolvimento do projeto, retrabalho, falta de padronização de mudança de escopo; tudo isso gerando custos adicionais não previstos no planejamento.

De acordo com Mendes (2015) projeto é um esforço temporário empreendido para criar um produto, serviço ou resultados únicos. Portanto a definição de projeto pressupõe uma data de início e fim. $\mathrm{O}$ ato de gerenciar projeto se caracteriza pelo planejamento adequado do tempo x atividades, para que o produto final seja entregue no tempo previsto e atinja as expectativas e objetivos que lhe foram propostos.

Dentro do gerenciamento de projetos existem várias possibilidades de monitoramento e controle em todas as áreas, dentre elas a área de risco. Lima (2005) desenvolve uma abordagem conceitual sobre o risco, definindo-o como o potencial para que eventos inesperados venham a acontecer ou para que eventos esperados não aconteçam, nos quais podem culminar em resultados adversos. De um modo ou de 
outro, o risco é um ponto fora do planejamento ideal, mas se for identificado antes que aconteça é possível diminuir os impactos gerados.

Analisando essa problemática e o princípio de que o design deve atuar em favor da dignidade humana, Buchanan (2001) apresenta-se uma plataforma que soluciona os principais problemas levantados. Um modelo colaborativo onde o cliente participa mais ativamente do projeto, diminuindo a probabilidade de uma entrega final insatisfatória. Foi implantado também um modelo de gerenciamento de projeto, como também uma gestão mais eficaz dos riscos. Acredita-se que um ambiente colaborativo somado a uma gestão eficiente aumentará a probabilidade de a entrega final superar as expectativas do cliente (evitando retrabalho), assim como, durante o processo, passar maior segurança do andamento do projeto através de um gerenciamento mais detalhado (aumentando a satisfação).

\section{METODOLOGIA}

Segundo Barbosa et. al. (2010) IHC, isto é, Interação Humano-Computador, é uma disciplina que tem por objetivo o projeto, implementação e avaliação dos sistemas computacionais interativos direcionados aos humanos. Esse método de desenvolvimento de interface é criado a partir do processo estabelecido para alcançam as características humanas. Brown (2008) demonstra que o uso dessa metodologia tem alcançado bons resultados tanto na área educacional como mercadológica. Criação inovadora de produtos, projetos, serviços e modelos são alguns exemplos de seguimentos impactados pela abordagem do IHC.

Nesse trabalho foram adotados os critérios de usabilidade de Jakob Nielsen, que são: (I) Visibilidade do estado do sistema; (II) Mapeamento entre sistema e mundo real, (III) Liberdade e controle do usuário; (IV) Consistência e padronização; (V) Prevenção de erros; (VI) Reconhecimento em vez de recordação; (VII) Flexibilidade e eficiência de uso; (VIII) Estética e design minimalista; (IX) Suporte para usuário reconhecer, diagnosticar e recuperar-se de erros; (X) Ajuda e documentação (NIELSEN e BUDIU, 2012). 
O HCD possui como princípio básico fornecer ajuda às atividades das pessoas, não importa o lugar, sempre envolvendo os usuários de design no processo de formação. IDEO (2014) afirma que projetar soluções inovadoras, relevantes, desejosas e comportamentais, exige um entendimento, a priori, das suas necessidades. A expectativa e as aspirações para o futuro também contam muito nesta decisão. Segundo Preece et. Al (2015) fornecer suporte às atividades das pessoas no lar, trabalho ou lazer é um pilar básico do IHC; sempre envolvendo os usuários nas soluções propostas, construindo o design colaborativamente.

\subsection{FASE OUVIR}

O processo de desenvolvimento baseado no Toolkit HCD inicia-se com o Desafio Estratégico, que neste caso foi definido da seguinte forma: "Como fornecer um meio de comunicação e acompanhamento de projetos arquitetônicos para arquitetos e clientes.", e prossegue com três fases principais, Ouvir, Criar e Implementar (que não será contemplada nesse artigo).

A fase inicial é a Ouvir, que consiste na busca de conhecimento através das pessoas, pois deve-se buscar ouvir e entender o que as pessoas querem (KUO, 2012), definindo quem deve ser questionado e como coletar as histórias dos potenciais usuários. Na primeira etapa dessa fase é definido o desafio estratégico, que busca entender de forma sucinta o problema e orientar a equipe em como desenvolver a entrevista de campo.

A etapa seguinte é a avaliação dos conhecimentos preexistentes, que consiste em avaliar o que já se sabe e o que não se sabe do desafio estratégico, sendo: Uma forma mais confiável e rápida de acompanhar e se comunicar dentro de um projeto arquitetônico; um aplicativo para dispositivo móvel que forneça esse meio de comunicação entre clientes e arquitetos; precisa-se descobrir se essa tecnologia vai resolver o problema da comunidade; precisa-se saber se as necessidades da comunidade serão supridas, baseado no que ela acha das ofertas disponíveis. 
A partir da etapa dos conhecimentos preexistentes, o próximo passo é definir as pessoas com quem conversar, ou seja, o público alvo escolhido para realizar a pesquisa de campo, pois sabe-se que o usuário é o verdadeiro especialista tratandose de suas próprias experiências (SANDERS, 2008). Esse público foi dividido em três membros, ideais, medianos e não ideais ou extremos opostos. Os membros ideais são aqueles que contratam arquitetos para realização de projetos e arquitetos que utilizam tecnologia para a comunicação sobre o projeto; os membros medianos são os que contratam arquitetos para realização de projetos e arquitetos que não utilizam tecnologias; os membros não ideais são as pessoas que nunca contrataram arquitetos para realização de projetos e que não têm interesse em contratar e arquitetos que não querem utilizar tecnologia.

$\mathrm{Na}$ etapa de escolher métodos de pesquisa, foram definidos quatro métodos: entrevistas individuais, que mostra pontos de vistas diferentes sobre as questões levantadas com a ideia do sistema; entrevistas em grupos, que mostra pontos de vistas compartilhados, faz com que cabeças e pontos de vistas diferentes se coloquem em conflito; entrevistas com experts, para buscar ideias e pontos de vista de quem trabalha na área e que conhece de perto as necessidades e os problemas encontrados no dia-a-dia do ambiente em que o sistema irá propor solução; busca de inspiração em novos locais, que consiste em observar possíveis aplicações para o sistema e novas ideias em locais que funcionam em um padrão parecido com que o nosso sistema aborda.

Nas entrevistas individuais, o método utilizado foi o de entrevistas presenciais com as pessoas que se encaixavam no perfil definido, buscando identificar possíveis usuários para o sistema e entender seus pontos de vista no problema que lhes foi apresentado. Nas entrevistas em grupos, foram divididos três grupos de cinco pessoas, com clientes e arquitetos, com o objetivo de que pontos de vistas coletivos fossem trazidos à tona e ajudassem na elaboração da solução.

As entrevistas com experts ajudaram a identificar os problemas técnicos da situação que estava sendo abordada, como o gerenciamento de versões do projeto e de seus artefatos. A busca de inspirações em novos locais serviu para que ideias em situações 
diferentes ajudassem a surgir novas soluções para os problemas encontrados. Essa busca foi realizada em que projetos que necessitam de acompanhamento, e nestes casos o versionamento compõe a parte fundamental para tal controle.

A etapa de desenvolvimento da abordagem de entrevista foi concluída baseada em três métodos: o guia de entrevista, conceitos sacrificiais e as técnicas de entrevistas. Esses métodos auxiliaram a realização da arrecadação de informações necessárias para colocar a ideia do sistema em prática.

O guia de entrevista, que é dividido entre questões de abertura, expansão e sondagem de profundidade, foi feito através de um questionário online que auxiliou a arrecadação dos dados. Nas questões de abertura, foram exploradas informações pessoais e o contato tecnológico de cada indivíduo. O objetivo desse primeiro momento é de adquirir informações básicas sobre o público alvo. Nas questões de expansão, as necessidades e os desejos do público alvo (arquitetos e clientes) foram exploradas. Nesta abordagem buscou-se entender os processos e as necessidades principais de ambos os lados.

Por último no guia de entrevista, na sondagem de profundidade, se questionou e abriu espaço para um diálogo a respeito das soluções propostas pela aplicação. Um espaço foi aberto, também, para eles proporem funcionalidades que ajudam em problemas que não vistos até então. Buscou-se entender a cultura tecnológica dessa linha de mercado, pesquisando a frequência de usabilidade de aplicativos e sistemas que auxiliem nos processos.

O conceito sacrificial foi visto nas perguntas direcionadas para criação de aplicativos. Dessa forma o arquiteto ou cliente entenderia o contexto de forma mais clara e real. A área tecnológica foi explorada de forma geral, não apenas aplicada a arquitetura. $A$ técnica utilizada "mostre-me", propôs ao entrevistado possíveis soluções para as questões levantadas por ele, explorou como o aplicativo ajudaria na solução do problema proposto por ele e tentou levar o entrevistado a uma consciência da necessidade de aplicativos no seu contexto. 
Na etapa "Desenvolver um modelo mental", um modelo foi desenvolvido com base na abordagem de observar vs. interpretar, sendo seguidos durante toda a fase ouvir do projeto. Toda vez que o foco das entrevistas e das pesquisas era perdido, e equipe buscava trazê-lo de volta com técnicas que não influenciassem os entrevistados.

\subsection{FASE CRIAR}

Após a primeira fase do projeto, a fase seguinte é a de trazer as ideias obtidas na fase ouvir para a realidade. Essa nova fase é chamada de Fase Criar, que propõe a interpretação dos dados obtidos durante a pesquisa e a criação de artefatos reais a partir dessa interpretação, como logotipo, fluxogramas, protótipos e a implementação final (que não será contemplada neste trabalho).

A fase criar é dividida em sete etapas: desenvolvimento da abordagem, compartilhamento de histórias, identificação de padrões que, por sua vez, é dividida na extração de insights principais, descobrimento de temas e criação de estruturas; criação de áreas de oportunidade, brainstorm de novas soluções, transformação de ideias em realidade e coleta de feedback.

A etapa inicial da fase criar é o desenvolvimento da abordagem, que consistiu em transformar a ideia para a solução do problema em um aplicativo e desenvolver seu logotipo. Architectural Management é um aplicativo que serve como um meio de comunicação rápido entre arquitetos e seus clientes. Ele apresenta uma interface amigável para quem deseja organizar seu projeto e acompanhá-lo junto com o arquiteto ou clientes. Conforme ilustra a Figura 1, a abordagem do logotipo busca mostrar o que o aplicativo irá representar para seus usuários, mostrando de forma rápida e simples o que ele significa e o que ele faz. No logotipo, conforme ilustrado na Figura 1, o compasso representa o "A" de Architectural e também remete ao uso do compasso como ferramenta de desenho na arquitetura. $\mathrm{O}$ "M" representa $\mathrm{O}$ Management do nome do sistema e, dentro do balão, representa a comunicação entre as partes na gerência dos projetos. 


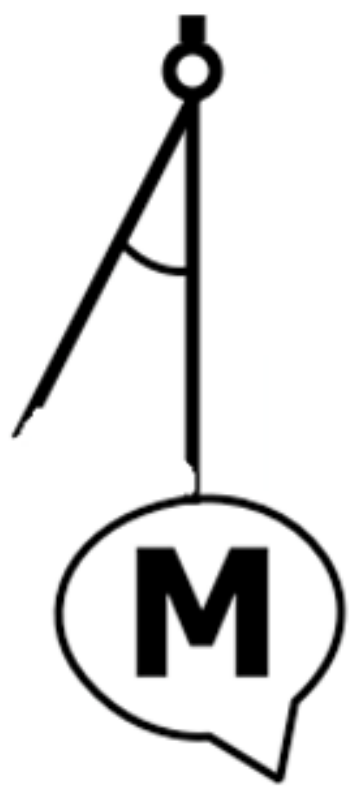

Figura 1: Logotipo do Architectural Management

Na segunda etapa, a do compartilhamento de histórias, as histórias coletadas durante a fase de pesquisa de campo (fase ouvir) são transformadas em informações e são utilizadas para criar oportunidades, ideias e soluções. Essas histórias foram: as pessoas (possíveis clientes) desejam participar ativamente no desenrolar de um projeto; a realização de quantas reuniões forem necessárias para a realização do projeto é uma ideia unânime entre os clientes; um meio de comunicação confiável e uma forma de visualização do projeto são indispensáveis no aplicativo; os clientes gostaram da ideia de existir um plano de risco; os clientes necessitam de meios de comunicação rápida com os arquitetos, notificações, gestão de tempo e de tarefas.

A etapa de identificação de padrões foi dividida em três métodos: extração de insights principais, descoberta de temas e criação de estruturas. Na extração de insights principais foi identificado que um dos itens inovadores do aplicativo é a gerência de risco. No entanto, todas as pessoas entrevistadas desconheciam esse conceito. Foi necessário explicar que o plano de risco consiste em criar um planejamento previsto de possíveis problemas com suas devidas soluções já definidas. Com esse planejamento há um melhor controle dos investimentos, tempo de entrega do projeto, dentre outras vantagens. 
Durante a descoberta de temas foi definido que há dois perfis diferentes e que cada um terá algumas funcionalidades restritas. Para os arquitetos são: criar projeto via formulário, gerenciar projeto via controle de atividades em checklist e abordagem de progressividade, adicionar clientes e arquitetos ao projeto, enviar plantas e planos de risco no ambiente colaborativo do aplicativo; e para os clientes, avaliar e ajustar plantas e planos de risco dentro do ambiente colaborativo do aplicativo. As demais funcionalidades são de uso comum das duas categorias/perfis: gerenciamento de contas pessoais dentro do aplicativo, bate-papo, pesquisa de usuários com contatos disponíveis de acordo com a privacidade definida em cada um.

A criação de estruturas veio com o objetivo de tornar mais compreensível os diferentes elementos do sistema, seus atores e seus relacionamentos. A figura 2 apresenta 0 fluxograma dos procedimentos básicos do sistema, de acordo com o perfil do arquiteto e seu ponto de vista dentro do aplicativo.

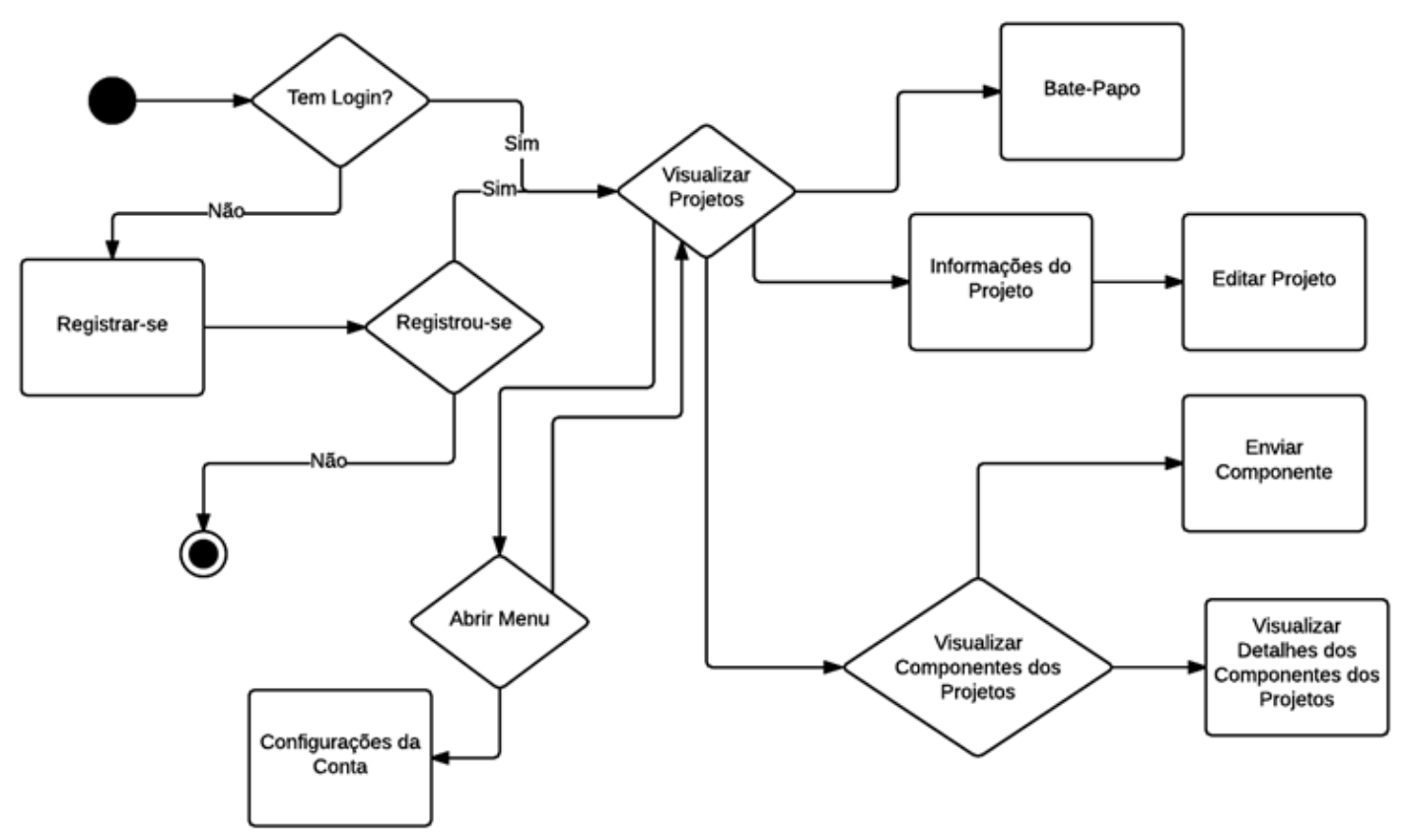

Figura 2: Fluxograma da visão do arquiteto

A criação de áreas de oportunidade busca traduzir o que já foi feito até então no projeto, os insights, temas e estruturas. Essas oportunidades são: acompanhamento 
de projeto de arquitetura online, plano de risco do projeto, versão para arquitetos, versão para clientes.

A etapa de brainstorm de novas soluções foi realizado para buscar soluções para os problemas apresentados pelas pessoas entrevistadas durante a fase ouvir, e funcionalidades foram criadas a partir dos problemas indicados, são elas: Criação de projeto, gerenciamento de projeto, controle de atividades em checklist, abordagem de progressividade, adição de clientes e arquitetos aos projetos, envio de plantas e planos de risco no ambiente colaborativo do aplicativo, avaliação e ajuste de plantas e planos de risco dentro do ambiente colaborativo do aplicativo, gerenciamento de contas pessoais dentro do aplicativo e bate-papo.

\section{RESULTADOS E DISCUSSÕES}

As ideias do aplicativo foram transformadas em realidade através de um protótipo. Criado na plataforma proto.io e desenvolvido com o intuito de mostrar o que se espera do aplicativo final e suas funcionalidades. A figura 3 apresenta 0 protótipo da tela de login, assim como as visões do menu principal do arquiteto e do cliente, consequentemente. 

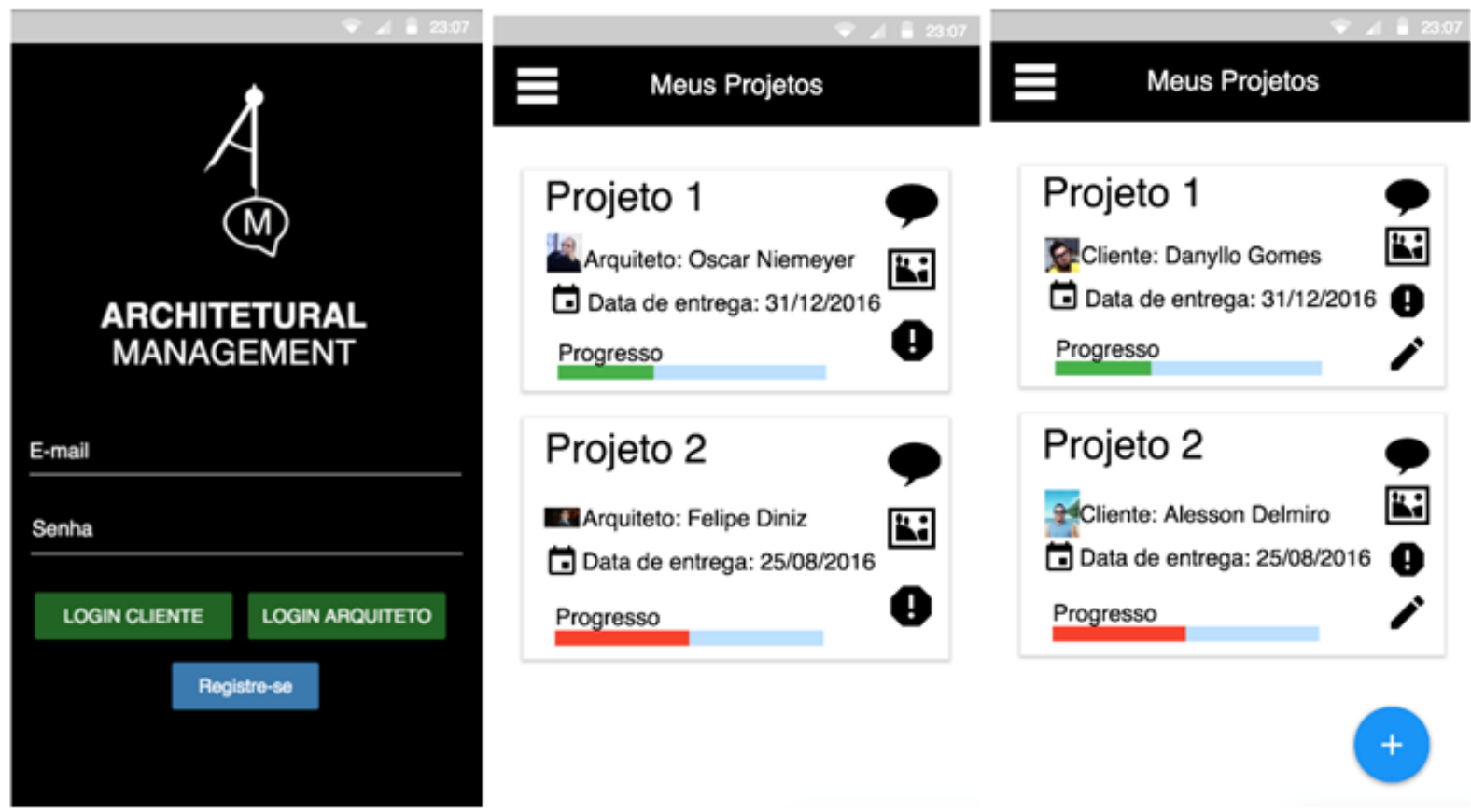

Figura 3: Protótipo mostrando tela de login e telas principais com as visões de arquiteto e cliente

Por último, a coleta de feedback, que foi realizada através de entrevistas presenciais e online para a obtenção de resultados e dados estatísticos. O formulário é dividido em 4 seções. A primeira seção é de perguntas gerais como nome e faixa etária; a segunda é específica para clientes ou arquitetos (cada uma só fica disponível para o perfil do respectivo usuário), e a terceira é de avaliação geral do protótipo.

Após o feedback, a equipe pôde ver quais funcionalidades estão melhores descritas e desenvolvidas, e quais podem ser melhoradas; se o logotipo representa a ideia proposta; quais funcionalidades que não foram contempladas no protótipo que poderiam ser importantes ou interessantes; se o sistema está simples e fácil de ser utilizado; se houve a necessidade um tutorial para o primeiro uso; se a quantidade de cliques para realização de cada tarefa ou ação é satisfatória; a avaliação da usabilidade e a navegação entre as funcionalidades do sistema; e se a ideia da aplicação é interessante. A figura 4 aborda o gráfico de avaliação do perfil do cliente. Como o perfil do arquiteto possui mais funcionalidades, se fez necessária uma pesquisa maior, conforme mostra a figura 5 . 


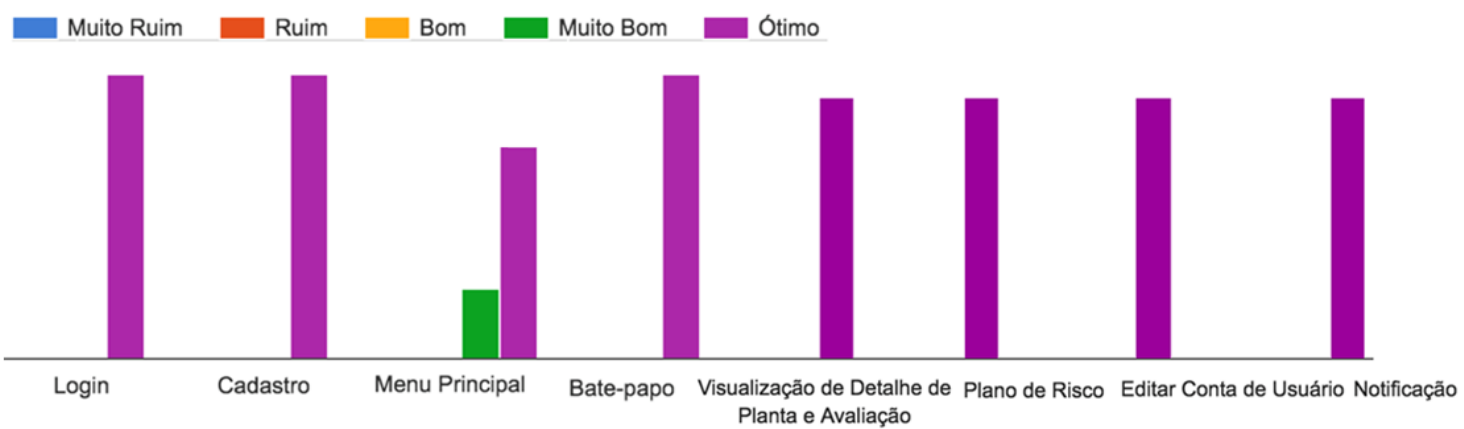

Figura 4: Gráfico de avaliação de funcionalidades da visão do cliente
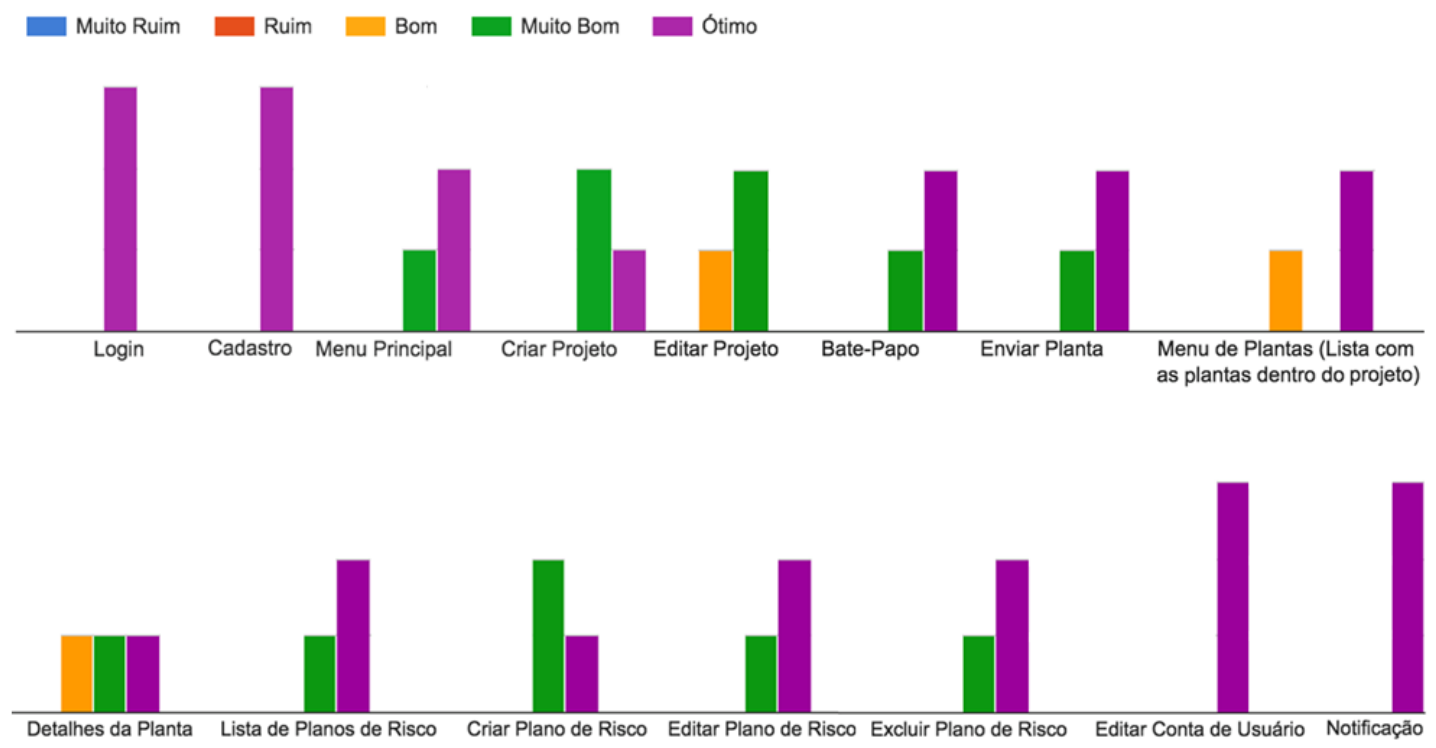

Figura 5: Gráfico de avaliação de funcionalidades da visão do arquiteto

De acordo os resultados apresentados, pode-se obter algumas conclusões: no usuário cliente, majoritariamente as funcionalidades foram aprovadas com melhor resultado. No usuário arquiteto, a maioria das funcionalidades tiveram uma ótima aceitação e as funcionalidades editar projeto e detalhes das plantas apresentaram resultado "bom", diferente de todas as outras. Acreditamos que seja por causa da quantidade de informações numa tela.

De forma geral, houve ótima aceitação no menu superior, quem não tem tanta familiaridade com tecnologia teve dificuldade em algumas interações, os clientes dos arquitetos demonstraram uma maior necessidade de tutorial do que os arquitetos, apesar de alegarem a necessidade de tutoriais, a aceitação da usabilidade foi positiva 
em ambos os perfis, houve cem por cento de aceitação na aprendizagem na primeira vez de utilização do aplicativo, mais da metade dos entrevistados teve uma experiência agradável, total aprovação na funcionalidade do bate-papo e todos afirmam que utilizariam e recomendariam o aplicativo. Houveram alguns pontos a melhorar, são eles: geração de relatório com indicadores de projeto, porcentagem para indicar o progresso, inclusão de mais detalhes do projeto, como, por exemplo, custos. A figura 6 apresenta de forma visual o resultado geral obtido pela pesquisa.

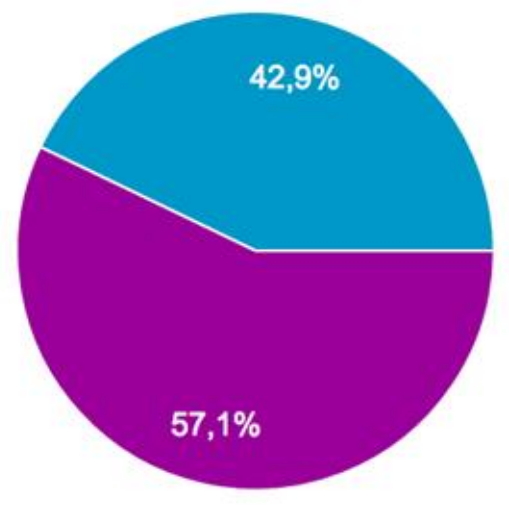

Muito ruim. Nunca utilizaria essa aplicação.

Ruim. Não gostei do protótipo.

Mediano. Está indo no caminho certo.

Bom. Está interessante, mas precisa melhorar em alguns aspectos.

Muito bom. Está faltando alguns pequenos detalhes.

Ótimo. Já pode começar a implementar.

Figura 6: Gráfico de avaliação do protótipo

Por meio das principais lojas de aplicativos (Google Play, App Store, Microsoft Store, entre outras) foram realizadas pesquisas de aplicativos de arquitetura com ideia semelhante a proposta por este trabalho, com destaque para dois deles: (I) Roomble 3D: permite o desenho de plantas, planejamento de ambientes, configuração e compra de móveis. As principais áreas abarcadas pelo aplicativo são: planejamento de ambientes, mobília e decoração, visualização de ideias, função de realidade aumentada, compartilhamento de plantas (nas redes sociais) e compra de móveis. $O$ aplicativo é dividido em área "grátis" e "professional". (II) Concepts: se apresenta como o aplicativo padrão de referencia de produtividade na era dos dispositivos móveis. Também possui um perfil pago que fornece: ferramentas de precisão, transformações avançadas, camadas infinitas, exportações e exportações para PDF, biblioteca de objetos. Para ambos os perfis o aplicativo fornece: interface simples e elegante, telas infinitas, 5 camadas, importação de imagens, projetos limitados. 
Observou-se que nenhum aplicativo possui a proposta de solução dos problemas elencados no início. Nenhum dos aplicativos une contato com o cliente, guarda de histórico, feedback online, planejamento de risco e acompanhamento de perto. A grande parte dos aplicativos voltados para essa área não fornecem uma plataforma de gerenciamento do projeto, dificultando ainda mais a manipulação do tempo e produtividade.

\section{CONCLUSÃO}

O desafio estratégico desenvolvido desde a fase Ouvir, norteando para o restante das fases foi fundamental para o desenvolvimento da solução. A metodologia fornecida pelo Toolkit HCD permitiu uma análise sistemática por meio de pesquisa de campo, questionário e entrevista. Através das informações obtidas nestas ferramentas tornouse possível uma modelação da solução tendo em vista o humano. Novas funcionalidades foram desenvolvidas por meio do feedback.

Tendo em vista o sucesso na fase Criar com a aprovação quase que unânime para prosseguir na implementação, chegou-se à conclusão que a proposta do protótipo foi um sucesso. Muitos arquitetos já demonstram interesse no aplicativo, apesar de não terem avaliado o processo. A explicação da ideia já era suficiente para despertar o interesse. Os próximos passos serão a implementação e a análise da viabilidade do esforço.

\section{REFERÊNCIAS}

MENDES, João Ricardo Barroca. Gerenciamento de projetos. Editora FGV, 2015.

BROWN T. Design Thinking. Harvard Business School Publishing, 2008.

NIELSEN, Jakob and BUDIU, Raluca. Mobile Usability. 1st ed. United States: New Riders Press, 2012

LIMA, Clóvis Ricardo Montenegro. Administração da assistência suplementar à saúde. Editora E-papers, 2005. 
BARBOSA, Simone; SILVA, Bruno. Interação humano-computador. Elsevier Brasil, 2010.

IDEO. (2014) Human Centered Design Toolkit. Tradução de Tennyson Pinheiro, José Colucci Júnior e Isabela de Melo. 2 ed. San Francisco, California/USA.

KUO, Cheng-Lang; YUAN, Cheng-Kang; LIU, Bor-Shong. Using human-centered design to improve the assault rifle. Applied ergonomics, v. 43, n. 6, p. 1002-1007, 2012.

BUCHANAN, Richard. Human dignity and human rights: Thoughts on the principles of human-centered design. Design issues, v. 17, n. 3, p. 35-39, 2001.

SANDERS, Liz. ON MODELING An evolving map of design practice and design research. interactions, v. 15, n. 6, p. 13-17, 2008.

PREECE J., SHARP H. AND ROGERS Y. (2015). Interaction Design: beyond humancomputer interaction. 4 edition. John Wiley \& Sons. 